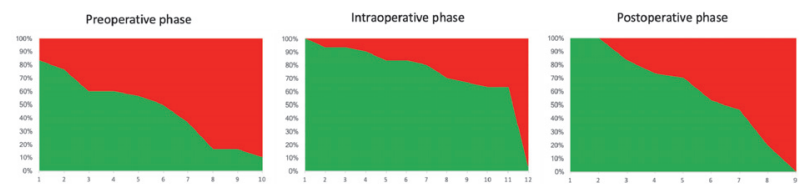

Abstract 93 Figure 1 Concordance between centres' behaviour and ERAS recommendations, expressed by rate of centres behaving in agreement with ERAS recommendations (agreement green; disagreement : red)

Methodology A 60-item questionnaire, covering the ERAS items for perioperative care in cytoreductive surgery, was sent to the responsible for each MITO/ManGO centre. Only questionnaires from centres reporting to operate $>20$ AOC per year were considered for the present analysis.

Result(s)* Thirty/30 (100\%) questionnaires from eligible centres were analysed. Survey main outcomes were presented and compared with the recommendations from the ERAS Society in table 1. Figure 1 graphically shows concordance between centres' current behaviour and ERAS recommendations, expressed by rate of concordance. In particular, $\geq 70 \%$ concordance (rate of centres behaving in agreement with ERAS recommendations) was observed in 2/10, 8/12, and 5/9 items, respectively for the pre, intra and postoperative phase. Conclusion* Although the recent attempts by the health providers to improve the management of AOC patients, this survey shows that further efforts should be made in order to optimize the perioperative pathway. This is true even in selected centres belonging to national oncological networks. There is a need for a structured peri-operative program specifically targeting AOC patients candidate to cytoreductive surgery.

\section{UNDERSTANDING CURRENT MULTIDISCIPLINARY TEAM STRUCTURES AND MANAGEMENT PRACTICES FOR ADVANCED OVARIAN CANCER IN THE UK: THE KNOW- OC SURVEY}

${ }^{1} \mathrm{C}$ Fotopoulou* ${ }^{*}{ }^{2} \mathrm{C}$ Gourley, ${ }^{3} \mathrm{~J}$ Ledermann, ${ }^{4} \mathrm{M}$ Hall, ${ }^{5} \mathrm{~J}$ Ayub, ${ }^{5} \mathrm{~L}$ Fildes, ${ }^{5} \mathrm{~N}$ Roebuck, ${ }^{6} \mathrm{R}$ Lord, ${ }^{7} \mathrm{R}$ Miller, ${ }^{8} \mathrm{~S}$ Sundar. ${ }^{1}$ Hammersmith Hospital, London, UK; ${ }^{2}$ Cancer Research UK Edinburgh Centre, Edinburgh, UK; ${ }^{3}$ UCL Cancer Institute and UCL Hospitals, London, UK; ${ }^{4}$ Mount Vernon Cancer Centre, Northwood, UK; ${ }^{5}$ GSK UK Ltd, Brentford, UK; ${ }^{6}$ Clatterbridge Cancer Centre - Liverpool, Liverpool, UK; ${ }^{7}$ University College London, London, UK; ${ }^{8}$ University of Birmingham, Birmingham, UK

\subsection{6/ijgc-2021-ESG0.339}

Introduction/Background* With increasing availability of multimodality treatment options for advanced ovarian cancer, the role of the multidisciplinary team (MDT) is key. Here, we aim to understand MDT structures and management practices relating to first line $\left(1^{\text {st }}\right.$-line $)$ systemic treatment for advanced ovarian cancer in the UK.

Methodology Structured telephone interviews about current MDT composition and treatment practices in alignment with European (ESMO/ESGO) consensus recommendations for advanced ovarian cancer were conducted in October/November 2020 with 66 healthcare professionals (HCPs) involved in the secondary care of ovarian cancer across the UK $(48.5 \%$ from specialist cancer centres).

Result(s)* Figure 1 and table 1 summarise the staff members regularly attending MDTs and responsibilities across the pathway. While the MDT reviewed $1^{\text {st }}$-line treatment options according to $98.5 \%$ of HCPs; only $66.7 \%$ and $40.9 \%$ said MDTs reviewed treatment after first or second relapse. Before planning $1^{\text {st }}$-line treatment, $C A-125 \quad$ (98.5\%), $\quad g B R C A$ $(\mathrm{n}=81.5 \%)$ and $t B R C A(76.9 \%)$ were the biomarkers most commonly assessed. $90.6 \% \quad(n=58 / 64)$ of HCPs considered $g B R C A / t B R C A$ results to be the most important determinant of prognosis. HRD was the second most important biomarker (55.9\%; $n=33 / 59)$, however, only three HCPs reported routine assessment. The estimated proportion of patients (median $[\mathrm{IQR}] ; \mathrm{n}=54)$ currently treated with $1^{\text {st }}$-line maintenance strategies was: 50\% [26.3-65.0\%] active surveillance; 20.0\% [11.3$33.8 \%]$ bevacizumab and 15\%[10.0-30.0\%] PARP inhibitor (PARPi). Anticipated future eligibility $(n=55)$ was: $35.0 \%$ [22.5-50.0\%]) PARPi maintenance monotherapy; 15.0\% [7.530.0\%] combination PARPi/bevacizumab; 20.0\% [10.0-32.5\%] active surveillance; $10.0 \%$ [8.5-20.0] bevacizumab alone.

Conclusion* The level of MDT involvement in the non-surgical management of advanced ovarian cancer varied depending on pathway and line of relapse. While almost all patients had input from an MDT at initial presentation, less than half of

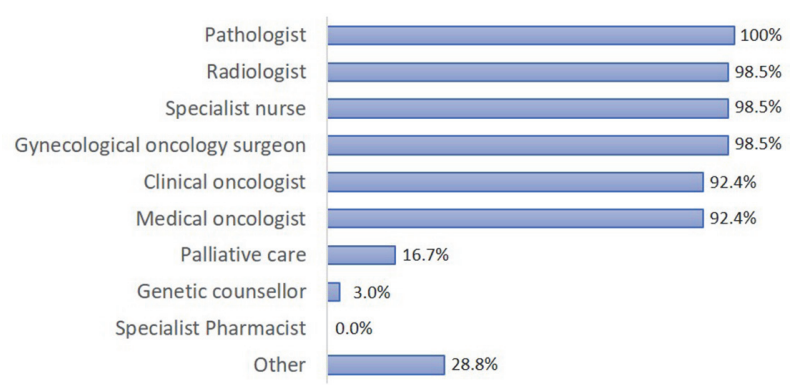

$\begin{array}{llllll}0 & 0 & 20\end{array} \quad 40 \% \quad 60 \% \quad 80 \% \quad 100 \%$

Abstract 109 Figure 1 Responses to question: "which specialties regularly ( $\geq 80 \%$ of time) attend the MDT?"

Abstract 109 Table 1 Responses to question: "Who has overall responsible for the clinical management of patients at each stage in the patient pathway?" ( $\mathrm{N}=66)$

\begin{tabular}{|c|c|c|c|c|c|c|c|}
\hline $\begin{array}{c}\text { Distribution of } \\
\text { ove rall } \\
\text { responsibilities } \\
\text { across pathway, } \\
n(\%)\end{array}$ & $\begin{array}{c}\text { Clinical Team/ } \\
\text { MDT }\end{array}$ & $\begin{array}{l}\text { Gynaecological } \\
\text { Oncology Surgeon }\end{array}$ & $\begin{array}{l}\text { Cancer Unit Lead } \\
\text { Consultant } \\
\text { Gynaecologist }\end{array}$ & Specialist Nurse & $\begin{array}{l}\text { Medical } \\
\text { Oncologist }\end{array}$ & Clinical Oncologist & Other \\
\hline Diagnosis & $18(27.3 \%)$ & $16(24.2 \%)$ & $25(37.9 \%)$ & $0(0.0 \%)$ & $0(0.0 \%)$ & $0(0.0 \%)$ & $7(10.6 \%)$ \\
\hline Staging & $45(68.2 \%)$ & $8(12.1 \%)$ & $8(12.1 \%)$ & $1(1.5 \%)$ & $0(0.0 \%)$ & $0(0.0 \%)$ & $4(6.1 \%)$ \\
\hline $\begin{array}{l}\text { Surgical } \\
\text { intervention }\end{array}$ & $8(12.1 \%)$ & $50(75.8 \%)$ & $6(9.1 \%)$ & $0(0.0 \%)$ & $0(0.0 \%)$ & $0(0.0 \%)$ & $2(3.0 \%)$ \\
\hline First Line & $19(28.8 \%)$ & $1(1.5 \%)$ & $2(3.0 \%)$ & $0(0.0 \%)$ & $28(42.4 \%)$ & $3(4.5 \%)$ & $13(19.7 \%)$ \\
\hline $\begin{array}{l}\text { Treatment at } \\
\text { recurrence }\end{array}$ & $19(28.8 \%)$ & $0(0.0 \%)$ & $0(0.0 \%)$ & $0(0.0 \%)$ & $34(51.5 \%)$ & $3(4.5 \%)$ & $10(15.2 \%)$ \\
\hline Palliative care & $17(25.8 \%)$ & $2(3.0 \%)$ & $0(0.0 \%)$ & $0(0.0 \%)$ & $17(25.8 \%)$ & $3(4.5 \%)$ & $27(40.9 \%)$ \\
\hline
\end{tabular}


the patients were discussed at an MDT when they experienced subsequent relapses indicating reduced access to a multidisciplinary care. BRCA mutation status was considered the most important biomarker. Whilst HRD status was also considered important, at the time of the survey this was not routinely assessed, highlighting issues with test availability. The use of active surveillance was expected to decrease in favour of targeted therapies such as PARPi as the treatment pathway evolves.

\section{EFFECT OF SURGICAL PARADIGM CHANGE ON OVERALL SURVIVAL IN PATIENTS WITH ADVANCED EPITHELIAL OVARIAN CANCER}

N Norppa*, S Saarelainen, S Staff, A Auranen. Tampere University Hospital, Department of Obstetrics and Gynecology, Tampere, Finland

\subsection{6/ijgc-2021-ESG0.340}

Introduction/Background* Ultra-radical procedures have been introduced into surgical treatment of advanced epithelial ovarian cancer to better reach the goal of resection of all visible tumor from the abdominal cavity. This has enabled surgical treatment for patients with advanced and more widespread disease. The aim of this study was to evaluate the effect of this change in surgical paradigm on overall survival.

Methodology We collected retrospectively 247 patients with FIGO Stage IIIB-IVB ovarian, tubal and primary peritoneal carcinoma operated between 2013 and 2019 either by primary or interval cytoreduction in Tampere University Hospital. Patients were categorized into two groups and compared based on the date of the operation. Group 1 was operated between January 2013 and February 2016. Group 2 was operated between March 2016 and March 2019, during which time the change in surgical approach occurred. Groups were similar in age, ASA classification, tumor histology and primary vs interval debulking surgery rate. Patients were followed up to November 2020.

Result(s)* Complete cytoreduction (R0) increased from 14\% to $54 \%$ in Stage III patients and from $23 \%$ to $49 \%$ in Stage IV patients after the change in surgical approach towards ultraradical surgery. The proportion rate of Stage IV patients increased slightly from $31 \%$ in Group 1 to $40 \%$ in Group 2 $(p=0.145)$. The median follow-up was 28.7 months (0.592.7). In all stages combined, the median OS increased from 33.5 months in Group 1 to 54.5 months in Group 2 $(p=0.028)$. The median OS for stage III patients in Group 1

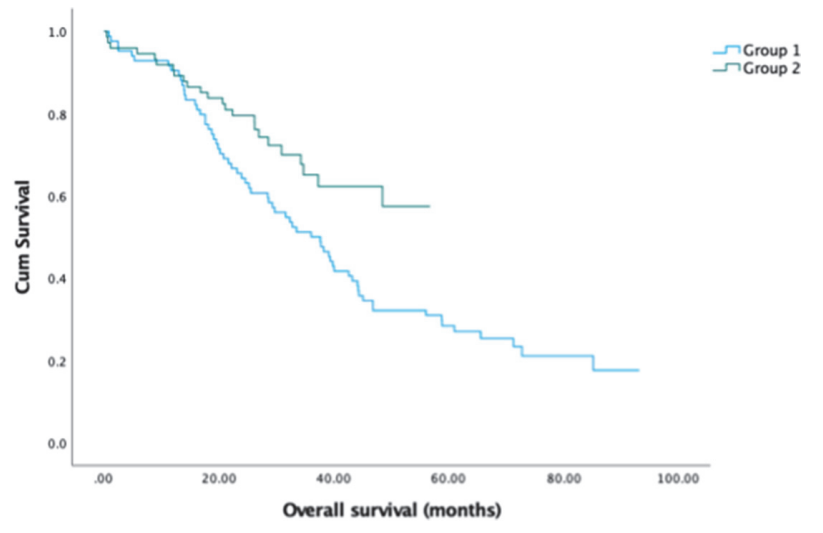

Abstract 121 Figure 1

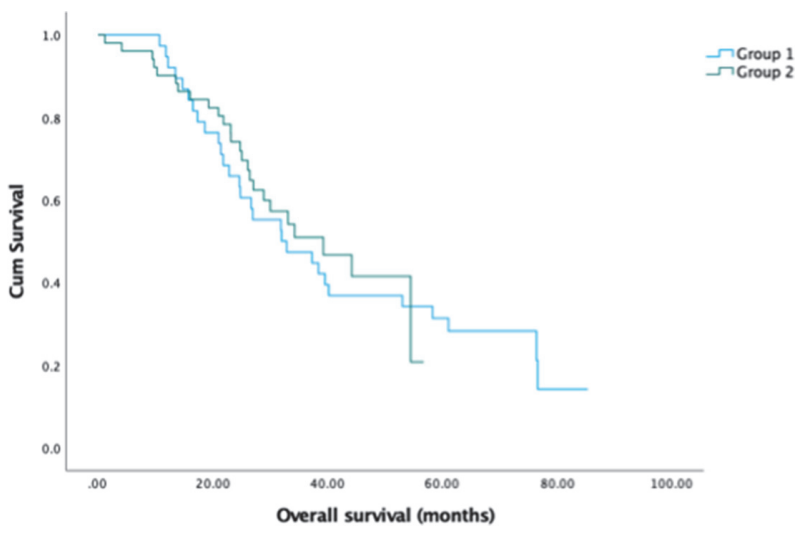

Abstract 121 Figure 2

was 36.1 months $(27.4$ - 44.8) but could not be reached in Group $2(\mathrm{p}=0.009)$. In Stage IV patients, OS was 32.0 months (16.4 - 47.7) and 39.3 months $(24.8$ - 53.8) in Group 1 and 2, respectively $(\mathrm{p}=0.691)$.

Conclusion* The change of surgical approach towards ultraradical techniques improves overall survival of patients with advanced epithelial ovarian cancer, but the survival benefit is only seen in stage III patients.

\section{PREOPERATIVE IMAGING ASSESSMENT OF PERITONEAL CANCER INDEX (PCI): CONCORDANCE WITH SURGICAL FINDINGS IN ADVANCED OVARIAN CANCER. A PROSPECTIVE STUDY}

${ }^{1} \mathrm{~S}$ Greggi*, ${ }^{2} \mathrm{O}$ Catalano, ${ }^{2} \mathrm{SV}$ Setola, ${ }^{1} \mathrm{G}$ Casella, ${ }^{1} \mathrm{G}$ Laurelli, ${ }^{1} \mathrm{~F}$ Scala, ${ }^{3} \mathrm{~V}$ Simeon, ${ }^{2} \mathrm{C}$ Granata, ${ }^{2} \mathrm{~A}$ Petrillo, ${ }^{1} \mathrm{C}$ Scaffa. ${ }^{1}$ Istituto Nazionale Tumori IRCCS "Fondazione G. Pascale", Department of Gynecologic Oncology, Naples, Italy; ${ }^{2}$ Istituto Nazionale Tumori IRCCS "Fondazione G. Pascale", Department of Radiology, Naples, Italy; ${ }^{3}$ Università degli Studi della Campania "Luigi Vanvitelli", Department of Medical Statistics, Naples, Italy

\subsection{6/ijgc-2021-ESGO.341}

Introduction/Background* The extent of peritoneal spread in advanced ovarian cancer (AOC) heavily impacts on the chance of a complete surgical cytoreduction. The decision-making process on the feasibility of cytoreductive surgery should include a dedicated imaging evaluation. The aim of this study was to prospectively compare a radiologic Peritoneal Cancer Index (rPCI) with the surgical PCI (sPCI).

Methodology 128 consecutive AOC patients planned for cytoreductive surgery underwent preoperative contrast-enhanced Computed Tomography (CT) scan to calculate the rPCI, then the sPCI was determined intraoperatively. CT scans were performed by two dedicated radiologists, and re-evaluated by a third. The rPCI correlation with sPCI was calculated by Lin's Concordance Correlation Coefficient (CCC), and represented by Bland-Altman agreement plot and Passing-Bablok regression line. Result(s)* Primary debulking surgery (PDS), and interval debulking surgery (IDS) were performed in 88 and 40 patients, respectively (complete cytoreduction in $56.8 \%$ PDS and $67.5 \%$ IDS). Overall, mean \pm SD rPCI was 16.2 \pm 6.4 (95\%CI:15.117.3) and sPCI 14.7 \pm 6.9 (95\%CI:13.5-15.9), showing a moderate correlation between preoperative CT scan and surgical findings (figures 1-2, CCC $=0.64$ ). The best concordance was reported for PDS vs. IDS (CCC $=0.64$ vs. 0.60$)$ and in middlehigh abdominal vs. low quadrants $(\mathrm{CCC}=0.57$ vs. 0.40$)$, while rPCI overestimated ileo-jejunal spread $(C C C=0.21)$. 